\title{
Metal Recovery from Nickel Metal Hydride Batteries Using Cyanex 923 in Tricaprylylmethylammonium Nitrate from Chloride Aqueous Media
}

\author{
Kristian Larsson $^{1} \cdot$ Koen Binnemans ${ }^{1}$
}

Published online: 21 April 2015

(C) The Minerals, Metals \& Materials Society (TMS) 2015

\begin{abstract}
A flow sheet has been developed for recovery of metals from nickel metal hydride batteries using the neutral extractant Cyanex 923 dissolved in the ionic liquid tricaprylylmethylammonium nitrate, $[\mathrm{A} 336]\left[\mathrm{NO}_{3}\right]$, and a synthetic chloride-based aqueous leach solution. The process allows purification of nickel in a single step by extracting chloride and nitrate complexes of the extractable transition metals and rare earths. Three selective strip operations utilizing first nitrate, stripping cobalt and manganese, and then chloride complexation, stripping the rare earths, followed by stripping of iron and zinc. Cobalt in the nitrate strip solution was separated from manganese by extraction with the ionic liquid tricaprylylmethylammonium thiocyanate, [A336][SCN].
\end{abstract}

Keywords Ionic liquids - Recycling - Solvent extraction · Split-anion extraction - Aliquat 336 - Cyanex 923 . Lanthanides $\cdot$ Nickel metal hydride $\cdot$ Rare earths

\section{Introduction}

End-of-life nickel metal hydride batteries are a valuable source of metals, including nickel, cobalt and rare earths. Nickel metal hydride batteries are an important high-volume application of rare earths [1]. The valuable metals in nickel metal hydride batteries are contained in the electrode materials, which can be treated separately or together depending on if the battery construction allows for a

Kristian Larsson

larsson.kristian@gmail.com

1 Department of Chemistry, KU Leuven, Celestijnenlaan 200F, Box 2404, 3001 Heverlee, Belgium physical separation [2]. The active cathode material is a mixture of hydroxides of mainly nickel and cobalt, with smaller amounts of zinc and yttrium. The active anode material is an alloy of primarily nickel, aluminium, cobalt and manganese with mischmetal ( $\mathrm{La}, \mathrm{Ce}, \mathrm{Pr}, \mathrm{Nd}$ ) and yttrium. Zhang et al. developed a recycling process for nickel metal hydride batteries, in which the battery materials were dissolved in $3 \mathrm{M}$ hydrochloric acid [3]. This was followed by extraction of rare earths with bis(2-ethylhexyl)phosphoric acid (D2EHPA) in kerosene, and separation of cobalt from nickel by extraction with trioctylamine in kerosene. Tzanetakis and Scott also used hydrochloric acid to dissolve batteries, and D2EHPA in kerosene was used to recover rare earths followed by electrochemical recovery of a nickel-cobalt alloy [4, 5]. Fernandes et al. developed a process involving concentrated chloride solutions for nickel metal hydride battery recycling, using the extractants tri- $n$-butyl phosphate (TBP), tri- $n$-octylamine (Alamine 336) and 2-ethylhexyl phosphonic acid mono-2ethylhexyl ester (PC-88A) to separate the metals, followed by precipitation of the metals as oxalates [6]. Previously, the first author developed and tested a process for nickel metal hydride recycling, based on dissolving the different electrode fractions in $8 \mathrm{M} \mathrm{HCl}$, and using the commercial extractant Cyanex 923 (consisting of a mixture of phosphine oxides) for extraction and separation of the valuable metals $[7,8]$.

Ionic liquids (ILs) can be an environment-friendlier alternative for molecular organic solvents in solvent extraction processes, either as extractants or diluents in the organic phase, due to their low vapor pressure and low flammability. Moreover, the extraction mechanism can differ in ionic liquids from that in molecular solvents, so that more efficient separation processes can be developed [9-15]. Ionic liquids can be immiscible with water or 
organic solvent (depending on the composition of the ionic liquid) and they are able to dissolve a wide range of organic and inorganic compounds [16]. Ionic liquids consist entirely of ions and are often composed of bulky organic cations and organic or inorganic anions. To be useful for solvent extraction, the ionic liquids also need to be in the liquid state at or near room temperature [17, 18].

Recently, we reported on a two-step ionic liquids process to recover metals from a solution based on the dissolution of electrode materials in $8 \mathrm{M} \mathrm{HCl}$ [19]. In a first step, cobalt, manganese, iron and zinc were extracted with the ionic liquid tricaprylylmethylammonium chloride (Aliquat 336, $[\mathrm{A} 336][\mathrm{Cl}])$. In the second step, the rare earths were extracted from the concentrated chloride solution by tricaprylylmethylammonium nitrate, $[\mathrm{A} 336]\left[\mathrm{NO}_{3}\right]$. In this paper, we extend our previous work with ionic liquids by further investigating the use of tricaprylylmethylammonium nitrate with (and without) the neutral extractant Cyanex 923 to extract metals directly from the starting aqueous phase. The ability of this nitrate-based ionic liquid to extract from chloride solutions is based on the fact that chloride ions have a higher affinity for the aqueous phase, while the nitrate ions have a higher affinity for the ionic liquid phase. This allows extraction of metals that form extractable nitrate complexes, such as rare-earth metals, from solutions that do not contain a significant amount of nitrate. This represents an example of so-called split-anion extraction [20]. The process is called split-anion extraction because the aqueous and organic phases comprise different anions. Nitrate and thiocyanate anions have a strong affinity for the organic phase, while chloride anions have a strong affinity for the aqueous phase [21]. This allows for the use of a complexing anion that forms an extractable complex without requiring a significant concentration of the complexing anion in the aqueous phase. This means that the aqueous phase can contain cheaper and more environmentally friendly anions such as chlorides or sulphates even for extraction systems where, for example, nitrates are required for extraction.

\section{Experimental}

\section{Chemicals}

Cyanex 923 (Cytec, $93 \%$ ) is a mixture of trialkylphosphine oxides with octyl and hexyl side groups: trioctylphosphine oxide, trihexylphosphine oxide and the mixed side group versions. Tricaprylylmethylammonium chloride (Aliquat 336, Sigma-Aldrich, 88.2-90.6\%, [A336][Cl]) is a mixture of quaternary ammonium salts, mainly trioctylmethylammonium chloride $(\mathrm{N}-\mathrm{N}$-dioctyl- $\mathrm{N}$ - methyl-1-octanaminium) and tridecylmethylammonium chloride $(N, N$-didecyl- $N$-methyl-1-decanaminium chloride). In order to prepare nitrate forms of the ionic liquid, tricaprylylmethylammonium nitrate $\left([\mathrm{A} 336]\left[\mathrm{NO}_{3}\right]\right)$, it was pre-equilibrated three times with a $2.5 \mathrm{M} \mathrm{KNO}_{3}$ solution to exchange the chloride ions for nitrate ions. Tricaprylylmethylammonium thiocyanate $([\mathrm{A} 336][\mathrm{SCN}]))$ was prepared by equilibrating twice with a $3 \mathrm{M} \mathrm{NH}_{4} \mathrm{SCN}$ solution to exchange the chloride ions for thiocyanate ions.

The following chemicals were used in preparation of solutions: Aluminium(III) chloride hexahydrate (Acros Organics, $99 \%$ ), cerium(III) chloride heptahydrate (Alfa Aesar, $99 \%$ ), cobalt(II) chloride hexahydrate (SigmaAldrich, $97 \%$ ), iron(III) chloride (Riedel-de Haën, $99 \%$ ), potassium chloride (AnalaR, > $99.5 \%$ ), lanthanum(III) chloride heptahydrate (Sigma-Aldrich, $99.9 \%$ ), magnesium(II) chloride (Sigma-Aldrich, > $98 \%$ ), manganese(II) chloride hexahydrate (Acros Organics, $97 \%$ ), neodymium(III) chloride hexahydrate (GFS chemicals, 99.9\%), nickel(II) chloride hexahydrate (Merck, $>98 \%$ ), praseodymium(III) chloride hexahydrate (Acros Organics, $99.9 \%$ ), yttrium(III) chloride hexahydrate (Heraeus, $99.9 \%$ ), zinc(II) chloride hexahydrate (SigmaAldrich, $99.999 \%$ ), sodium nitrate (Chem-Lab, > $99 \%$ ), ammonia ( $25 \%$ (w/v), Chem-lab), magnesium chloride (Sigma-Aldrich, $>98 \%$ ), ammonium thiocyanate (Sigma-Aldrich, >99\%), pure water (MilliQ, Millipore, $>18 \mathrm{M} \Omega \mathrm{cm}^{-1}$ ) was used for all dilutions.

\section{Analysis}

A Bruker S2 Picofox total reflection X-ray fluorescence (TXRF) spectrometer was used to determine the metal content in solutions. The uncertainties given are one standard deviation based on differences in triplicate measurements, i.e. the standard deviation for the measurement replication. Viscosity measurements were performed using an automatic Brookfield plate cone viscometer, Model LVDV-II+P CP (Brookfield Engineering Laboratories, USA). The initial aqueous solution prepared for extraction studies was based on the composition of mixed electrodes from a hybrid electric vehicle (HEV) NiMH battery dissolved in $8 \mathrm{M}$ hydrochloric acid, as described previously by Larsson et al. [2]. Concentrations for the aqueous solutions are shown in Table 1 (TXRF measurement results). Magnesium and aluminium concentrations could not be reliably determined by TXRF at the concentrations in the prepared solutions and are therefore present in the solutions in order to mimic real solutions but no extraction data could be reported. Potassium extraction was close to or below detection limits in the ionic liquid phase for all experiments. 
Table 1 TXRF measurement of starting aqueous solutions in molar concentrations

\begin{tabular}{lc}
\hline Metal & Conc. (M) \\
\hline $\mathrm{Co}$ & $0.47 \pm 0.01$ \\
$\mathrm{Mn}$ & $0.13 \pm 0.01$ \\
$\mathrm{~K}$ & $0.08 \pm 0.004$ \\
$\mathrm{Y}$ & $0.04 \pm 0.002$ \\
$\mathrm{Ce}$ & $0.08 \pm 0.002$ \\
$\mathrm{Nd}$ & $0.02 \pm 0.001$ \\
$\mathrm{Fe}$ & $0.04 \pm 0.002$ \\
$\mathrm{Zn}$ & $0.02 \pm 0.001$ \\
$\mathrm{Ni}$ & $3.0 \pm 0.10$ \\
$\mathrm{La}$ & $0.25 \pm 0.01$ \\
$\mathrm{Pr}$ & $0.01 \pm 0.0004$ \\
\hline Aluminium & (approximately \\
0.1 M) and & magnesium (ap- \\
proximately & 0.04 M) were also \\
present in all the solutions
\end{tabular}

Solvent Extraction Procedure

Batch solvent extraction experiments were performed using approximately $1 \mathrm{~mL}$ of each phase, unless other phase ratios were tested, in which case the ionic liquid volume was increased. Samples were shaken at constant temperature using a TMS-200 turbo thermo shaker (Hangzhou Allsheng Instruments Co., Ltd) for $30 \mathrm{~min}$, or longer where stated. Larger extraction experiments used $30 \mathrm{~mL}$ to make the treated phases for further experiments.

The distribution ratio $(D)$ of a single metal is defined (Eq. 1) as the ratio of the total concentration in the ionic liquid phase $\left([\mathrm{M}]_{\mathrm{IL}}\right)$ to the total concentration in the aqueous phase $\left([\mathrm{M}]_{\mathrm{aq}}\right)$ after extraction and phase separation. The phase ratios are defined as the volume ionic liquid divided by the volume aqueous phase. The percentage extracted $(\% E)$ is defined in Eq. 2, where $\mathrm{V}_{\mathrm{aq}}$ and $\mathrm{V}_{\mathrm{IL}}$ are the volumes of the aqueous and ionic liquid phases, respectively. The phase ratio $(\Theta)$ is defined in Eq. 3 .

$$
\begin{aligned}
& D=\frac{[\mathrm{M}]_{\mathrm{IL}}}{[\mathrm{M}]_{\mathrm{aq}}} \\
& \% E=\frac{100 \cdot D}{D+\frac{\mathrm{V}_{\mathrm{aq}}}{\mathrm{V}_{\mathrm{IL}}}} \\
& \Theta=\frac{\mathrm{V}_{\mathrm{IL}}}{\mathrm{V}_{\mathrm{aq}}} .
\end{aligned}
$$

\section{Results}

\section{Metal Extraction}

The direct application of $[\mathrm{A} 336]\left[\mathrm{NO}_{3}\right]$ on the synthetic aqueous solution mimicking a dissolved battery gave
Table 2 Distribution ratios for extraction with [A336] $\left[\mathrm{NO}_{3}\right]$ on the starting aqueous solution

\begin{tabular}{lc}
\hline Metal & $D$ \\
\hline $\mathrm{Co}$ & $17 \pm 2.7$ \\
$\mathrm{Fe}$ & $3.2 \pm 0.9$ \\
$\mathrm{Mn}$ & $2.7 \pm 0.5$ \\
$\mathrm{Ni}$ & $0.01 \pm 0.004$ \\
$\mathrm{Y}$ & $0.3 \pm 0.01$ \\
$\mathrm{La}$ & $17 \pm 7.8$ \\
$\mathrm{Ce}$ & $23 \pm 15$ \\
$\mathrm{Pr}$ & $2.5 \pm 0.6$ \\
$\mathrm{Nd}$ & $1.7 \pm 0.3$ \\
\hline Zinc was fully extracted. A & phase ratio of 2:1 ( $\left.\mathrm{V}_{\mathrm{IL}}: \mathrm{V}_{\mathrm{aq}}\right)$ \\
was used at $50^{\circ} \mathrm{C}$ and $1 \mathrm{~h}$ of \\
mixing (3000 rpm)
\end{tabular}

distribution ratios at equilibrium that were acceptable for $\mathrm{Co}, \mathrm{Zn}, \mathrm{La}$ and $\mathrm{Ce}$, but somewhat too low for Fe, Mn, Y, Pr and $\mathrm{Nd}$ (Table 2). The distribution ratios could be raised by increasing the chloride content in the aqueous solution through additional magnesium chloride or by refluxing part of the aqueous flow after extraction and thereby increasing the nickel chloride content. This way of changing the chloride concentration is somewhat less desirable than adding an extractant in order to raise the distribution ratios. However, it is a viable way if extractants need to be avoided. The fact that the distribution ratios are not too high also indicates that the stripping will be relatively easy.

The neutral extractant Cyanex 923 was added to the [A336] $\left[\mathrm{NO}_{3}\right]$ solution in order to raise the distribution ratios. A level of $15 \%$ Cyanex $923(\mathrm{v} / \mathrm{v})$ in [A336] $\left[\mathrm{NO}_{3}\right]$ was chosen since it sufficiently increased the distribution ratios. The amount of Cyanex 923 can however be optimized for each specific case and will depend on the composition of the aqueous feed. The rare-earth metals and zinc were all below detection limits in the aqueous phase after equilibration. The distribution ratios at equilibrium for the remaining metals are shown in Table 3. The extraction of nickel was low compared to the metals with high distribution ratios, so the separation factors were high.

In order to show that the systems can reach equilibrium relatively fast, a time-dependent experiment with the same experimental conditions as before, a phase ratio of 2:1 and $50^{\circ} \mathrm{C}$, with mixing at $3000 \mathrm{rpm}$ was performed (Fig. 1, for clarity only lanthanum, yttrium and cobalt are shown). The lanthanum is fairly representative of the rare-earth extraction behaviour, except for that of yttrium. The conclusion from the experiment was that equilibrium can be reached within 12 min of mixing; however, the relatively high viscosity of the ionic liquid phase requires vigorous shaking. The yttrium extraction at equilibrium reached only $50 \%$ in the pure $[\mathrm{A} 336]\left[\mathrm{NO}_{3}\right]$ ionic liquid, which could be expected since the yttrium extraction is lower than the light 
Table 3 Distribution ratios for extraction of the starting aqueous solution with Cyanex $923(15 \% \mathrm{v} / \mathrm{v})$ dissolved in [A336] $\left[\mathrm{NO}_{3}\right]$

\begin{tabular}{lc}
\hline Metal & $D$ \\
\hline Co & $36 \pm 1.4$ \\
Mn & $4.2 \pm 0.1$ \\
Fe & $7.4 \pm 0.1$ \\
$\mathrm{Ni}$ & $0.01 \pm 0.003$
\end{tabular}

Rare earths and zinc were fully extracted. A phase ratio of $2: 1$ $\left(\mathrm{V}_{\mathrm{IL}}: \mathrm{V}_{\mathrm{aq}}\right)$ was used at $50^{\circ} \mathrm{C}$ and $2 \mathrm{~h}$ of mixing $(2200 \mathrm{rpm})$

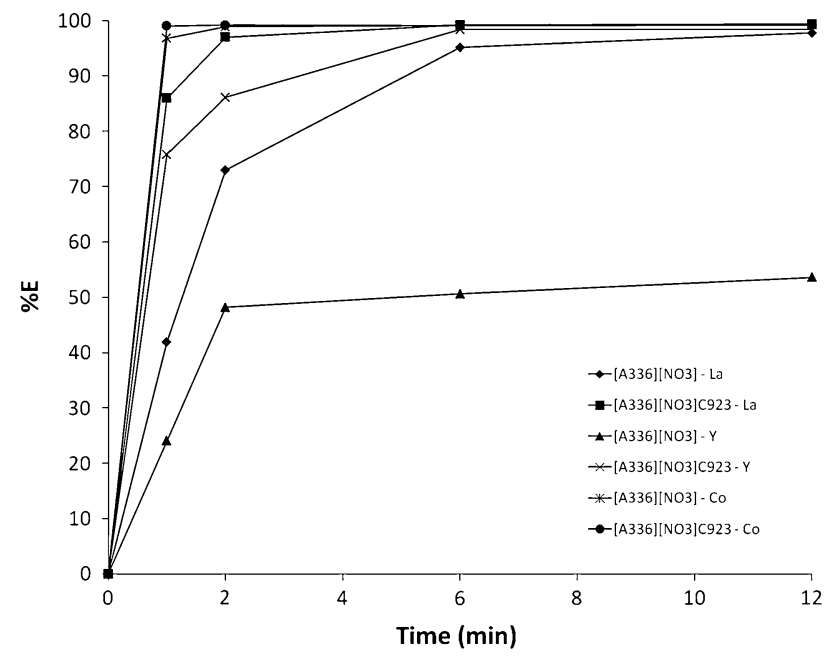

Fig. 1 Kinetics experiment showing the percentage extraction for [A336] $\left[\mathrm{NO}_{3}\right]$ with and without $15 \%(\mathrm{v} / \mathrm{v})$ Cyanex 923 at mixing speed $3000 \mathrm{rpm}$, at $50^{\circ} \mathrm{C}$ with a phase ratio of $2: 1\left(\mathrm{~V}_{\mathrm{IL}}: \mathrm{V}_{\mathrm{aq}}\right)$

rare earths in pure nitrate systems; however, the extraction speed is relatively fast.

To increase the purity of the extract with regard to especially nickel, it was scrubbed three times using $4 \mathrm{M}$ magnesium chloride at a phase ratio of 10:1 (Table 4). This removed more than $98 \%$ of the extracted nickel. Additional steps or a lower phase ratio can remove more. The rare earths and zinc remained fully extracted during scrubbing. Magnesium chloride was chosen as a source of chloride to maintain extraction since the battery material already contained magnesium and it would be possible to re-enter it into the process without adding a new impurity. The high magnesium chloride concentration was used to maintain close to full extraction; however, a lower concentration could have been used since the stream can be reentered into either the dissolution step or initial extraction step without loss of material.

When stripping the scrubbed extract with $3 \mathrm{M}$ sodium nitrate, the rare earths, iron and zinc remained extracted, while cobalt and manganese were effectively stripped from the ionic liquid phase (Table 5). After each step, the
Table 4 Distribution ratios for scrubbing the extracted phase using 4 $\mathrm{M} \mathrm{MgCl}_{2}$ solution

\begin{tabular}{lccc}
\hline Metal & Step $1(D)$ & Step 2 $(D)$ & Step 3 $(D)$ \\
\hline Co & $1530 \pm 55$ & $1870 \pm 460$ & $2680 \pm 78$ \\
$\mathrm{Fe}$ & $30 \pm 26$ & $180 \pm 51$ & $82 \pm 33$ \\
$\mathrm{Mn}$ & $79 \pm 2$ & $180 \pm 13$ & $260 \pm 6$ \\
$\mathrm{Ni}$ & $0.026 \pm 0.003$ & $0.036 \pm 0.001$ & $0.032 \pm 0.002$ \\
\hline
\end{tabular}

The rare earths and zinc were below detection limits in the aqueous phase. A phase ratio of 10:1 $\left(\mathrm{V}_{\mathrm{IL}}: \mathrm{V}_{\mathrm{aq}}\right)$ was used three times at $2 \mathrm{~h}$ of mixing $(2200 \mathrm{rpm})$ at $50^{\circ} \mathrm{C}$

Table 5 Distribution ratios for stripping the scrubbed phase using 3 $\mathrm{M} \mathrm{NaNO}$ solution

\begin{tabular}{llcc}
\hline Metal & Step $1(D) 1: 2$ & Step 2 $(D) 1: 2$ & Step 3 $(D) 1: 6$ \\
\hline Co & $0.21 \pm 0.02$ & $0.012 \pm 0.001$ & $0.005 \pm 0.002$ \\
Fe & $62 \pm 30$ & $141 \pm 38$ & $27 \pm 2$ \\
Mn & $0.08 \pm 0.01$ & $0.035 \pm 0.004$ & $0.08 \pm 0.01$ \\
Zn & n.d. in aq & $69 \pm 2$ & $4 \pm 0.2$ \\
Y & $52 \pm 5$ & $27 \pm 1$ & $12 \pm 1$ \\
La & $250 \pm 38$ & $170 \pm 30$ & $78 \pm 20$ \\
Ce & $290 \pm 160$ & $190 \pm 60$ & $96 \pm 18$ \\
Pr & $79 \pm 81$ & $44 \pm 2$ & $43 \pm 3$ \\
Nd & $53 \pm 28$ & $76 \pm 15$ & $51 \pm 8$ \\
\hline A phas &
\end{tabular}

A phase ratio of $1: 2$ followed by $1: 2$ and $1: 6$ was used with $2 \mathrm{~h}$ of mixing at $50{ }^{\circ} \mathrm{C}$

${ }^{\text {a }}$ n.d. in aq $=$ Not detected in the aqueous phase

chloride level decreased and the zinc distribution ratio decreased. Zinc could thereby be selectively stripped after the manganese and cobalt with additional nitrate strip steps; this route was, however, not used. The zinc distribution ratios can be raised by adding a small amount of chloride to the aqueous phase to limit stripping of iron and zinc.

The strip phase from the first step was used in an experiment to separate cobalt from manganese using [A336][SCN] dissolved in [A336] $\left[\mathrm{NO}_{3}\right.$ ] (Fig. 2). Considering the distribution ratios, $40 \%$ was deemed a sufficient thiocyanate percentage in the ionic liquid phase to extract cobalt from manganese. This gave a distribution ratio of approximately 40 (significant extraction) and a separation factor of 920. Higher thiocyanate concentrations give higher distribution ratios and separation factors, however, that can make the strip more difficult, and a low thiocyanate concentration can be preferential due to stability issues. The co-extracted manganese could easily be scrubbed with water and cobalt subsequently stripped using ammonia. 


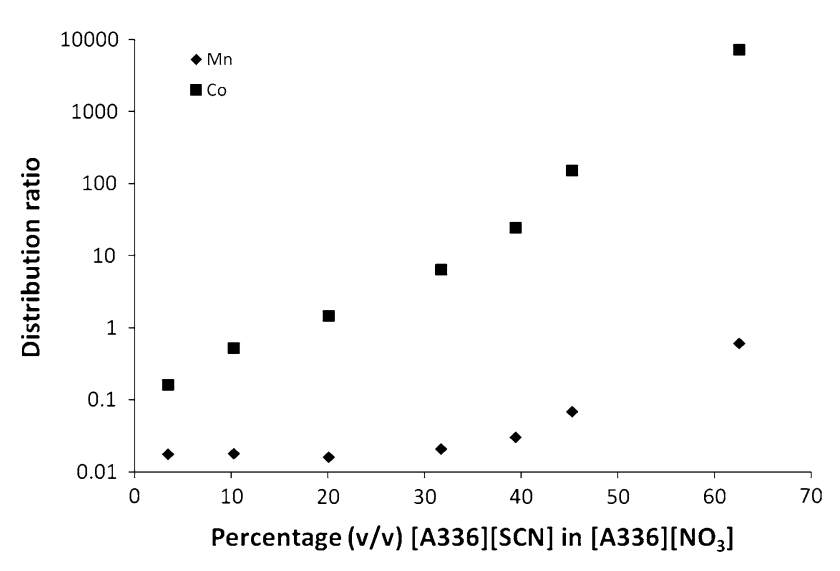

Fig. 2 Distribution ratios for cobalt and manganese with the percentage $(\mathrm{v} / \mathrm{v})$ of $[\mathrm{A} 336][\mathrm{SCN}]$ dissolved in $[\mathrm{A} 336]\left[\mathrm{NO}_{3}\right]$ after $30 \mathrm{~min}$ and $3000 \mathrm{rpm}$ mixing at $30^{\circ} \mathrm{C}$

Using an acidic chloride strip $(1 \mathrm{M} \mathrm{HCl})$ for the second strip on the ionic liquid phase, iron and zinc remained extracted, while rare earths were effectively stripped from the ionic liquid phase (Table 6). Since the distribution ratios of this acidic strip are quite low, a higher Cyanex 923 level could be used without necessarily having a negative influence on the stripping, if distribution ratios need to be raised in the initial stages.

Using a nitric acid strip $\left(1 \mathrm{M} \mathrm{HNO}_{3}\right)$, iron and zinc were stripped from the ionic liquid phase while exchanging chloride anions in the ionic liquid for nitrate anions (Table 7). Water was also a possible strip solution; however, the nitrate solution regenerates the ionic liquid to its nitrate form. In case the stripping is considered insufficient using nitric acid, ammonia was very effective in removing zinc and iron from the ionic liquid phase.

An ionic liquid phase with a relatively low viscosity is required for solvent extraction. The viscosity of the ionic liquid phase can be lowered by an increase in temperature. Fig. 3 shows the viscosity for the ionic liquid phase in two cases, the high loading after the scrub and the lightly

Table 6 Distribution ratios for stripping the ionic liquid phase after the first strip using $1 \mathrm{M} \mathrm{HCl}$ solution

\begin{tabular}{lccc}
\hline Metal & Step $1(D) 1: 2$ & Step 2 $(D) 1: 2$ & Step 3 $(D) 1: 2$ \\
\hline $\mathrm{Fe}$ & $53 \pm 37$ & $230 \pm 310$ & $16 \pm 0.3$ \\
$\mathrm{Zn}$ & $230 \pm 66$ & $430 \pm 110$ & $680 \pm 110$ \\
$\mathrm{Y}$ & $0.13 \pm 0.01$ & $0.06 \pm 0.004$ & $0.01 \pm 0.01$ \\
$\mathrm{La}$ & $0.32 \pm 0.03$ & $0.12 \pm 0.01$ & $0.06 \pm 0.004$ \\
$\mathrm{Ce}$ & $0.46 \pm 0.07$ & $0.2 \pm 0.01$ & $0.10 \pm 0.01$ \\
$\mathrm{Pr}$ & $0.52 \pm 0.13$ & $0.25 \pm 0.03$ & $0.13 \pm 0.01$ \\
$\mathrm{Nd}$ & $0.60 \pm 0.06$ & $0.23 \pm 0.01$ & $0.13 \pm 0.004$ \\
\hline
\end{tabular}

A phase ratio of $1: 2$ was used three times with $2 \mathrm{~h}$ of mixing (2200 rpm) at $50^{\circ} \mathrm{C}$
Table 7 Distribution ratios for stripping the twice-stripped ionic liquid phase using $1 \mathrm{M} \mathrm{HNO}_{3}$ solution

\begin{tabular}{lccl}
\hline Metal & Step 1 $(D) 1: 2$ & Step 2 $(D) 1: 2$ & Step 3 $(D) 1: 2$ \\
\hline $\mathrm{Fe}$ & $3.7 \pm 0.54$ & $0.40 \pm 0.01$ & $0.26 \pm 0.01$ \\
$\mathrm{Zn}$ & $29 \pm 0.31$ & $1.2 \pm 0.05$ & $0.09 \pm 0.002$ \\
\hline
\end{tabular}

A phase ratio of $1: 2$ followed by $1: 2$ and $1: 6$ was used with $2 \mathrm{~h}$ of mixing $(2200 \mathrm{rpm})$ at $50^{\circ} \mathrm{C}$

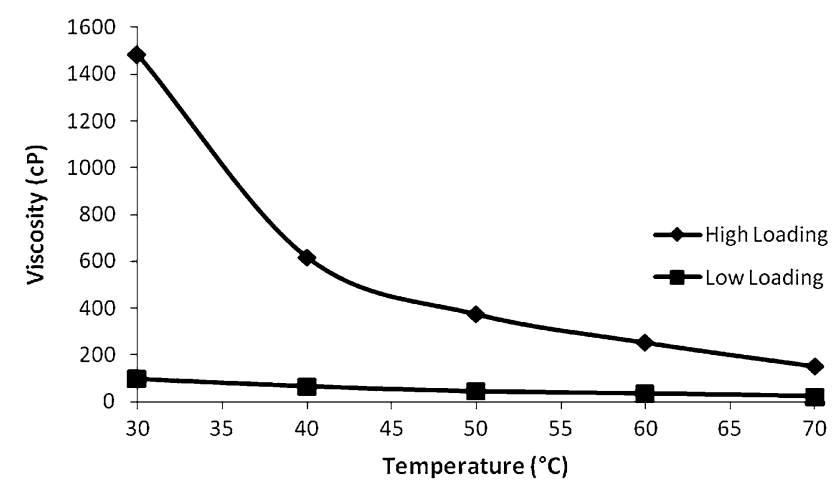

Fig. 3 Viscosity (cP) for the solvent with $15 \%$ Cyanex 923 in [A336] $\left[\mathrm{NO}_{3}\right]$ at high loading (after the first scrub) and at low loading (after the second strip)

loaded phase after the second strip. A temperature of $50^{\circ} \mathrm{C}$ was used for most of the experiments since this temperature gave sufficiently low viscosity for testing purposes.

\section{Discussion}

The process scheme shown in Fig. 4 makes use of [A336] $\left[\mathrm{NO}_{3}\right]$ with Cyanex 923 to extract rare earths, cobalt, iron, manganese and zinc from a concentrated chloride solution. The loaded ionic liquid phase is scrubbed using a concentrated magnesium chloride solution at a very high phase ratio $\left(\mathrm{V}_{\mathrm{IL}}: \mathrm{V}_{\mathrm{aq}}\right)$. The high chloride concentration gives high distribution ratios for the extracted metals, while scrubbing nickel. The aqueous phase from the scrub can be re-entered into the extraction step since the magnesium and nickel will end up in raffinate $\mathbf{1}$, while any other scrubbed metal will be recovered in the extraction step. The scrubbed phase is stripped from cobalt and manganese using $3 \mathrm{M}$ sodium nitrate, where the nitrate keeps the rare earths extracted. The singly stripped phase is stripped of rare earths in strip 2 using an acidic solution $(1 \mathrm{M} \mathrm{HCl})$. The chloride content keeps the zinc and iron extracted. The doubly stripped phase is stripped of iron and zinc with nitric acid, which also regenerates the solvent so 


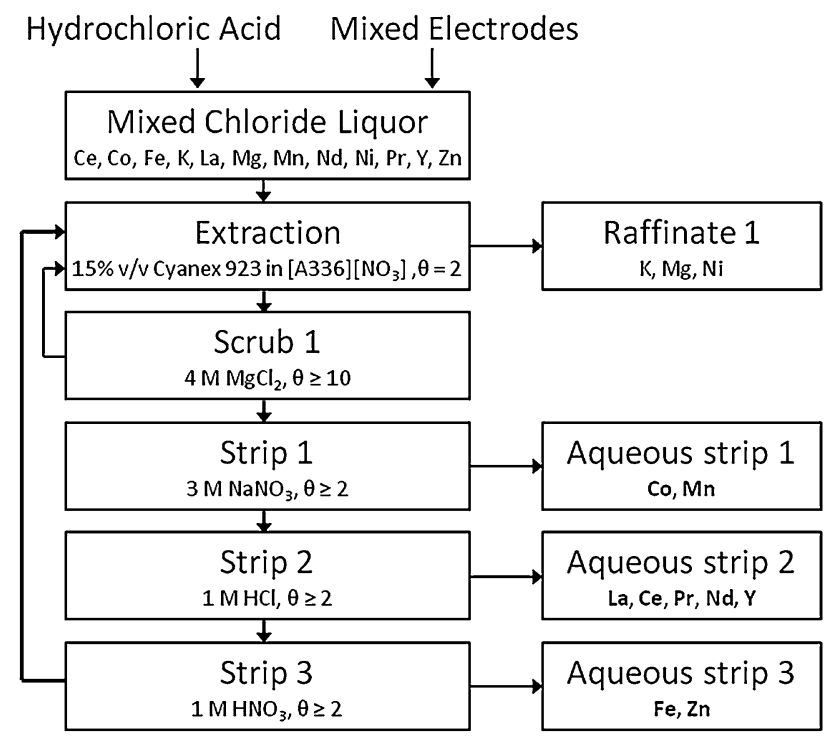

Fig. 4 Flow sheet describing the extraction and stripping steps and the resulting ionic liquid and aqueous streams

it can be re-entered into the initial extraction, the strip can also be performed using ammonia. Alternatively, zinc and iron can be extracted from the initial chloride solution using diluted Cyanex 923 or TBP [8]. The strip and scrub step experiments requiring multiple steps were performed consecutively in three steps. In an industrial setting, however, the process steps will likely be performed in a continuous set-up. The entire process was tested without Cyanex 923 as well (pure [A336] $\left[\mathrm{NO}_{3}\right]$ ) and was functional but the lower distribution ratios gave lower separation factors and less pure streams. The distribution ratios could be raised using additional matrix, adding, for example, additional magnesium chloride in the extraction step to raise the chloride concentration. However, the phase with $15 \%$ (v/v) Cyanex 923 was deemed more efficient, this could change in a cost-based optimization.

The cobalt and manganese in the stream from aqueous strip 1 can be separated according to the scheme in Fig. 5 . [A336][SCN] is used to extract cobalt, while [A336] $\left[\mathrm{NO}_{3}\right]$ acts as an ionic liquid diluent. Any extracted manganese is easily stripped using water, and cobalt is subsequently stripped using ammonia.

\section{Conclusions}

The combination of $[\mathrm{A} 336]\left[\mathrm{NO}_{3}\right]$ and Cyanex 923 has excellent properties for extracting cobalt, manganese, iron, zinc and rare earths from a concentrated chloride solution derived from dissolved electrode materials of nickel metal hydride batteries. The synthetic aqueous solution of dissolved batteries contained only chloride ions, while the

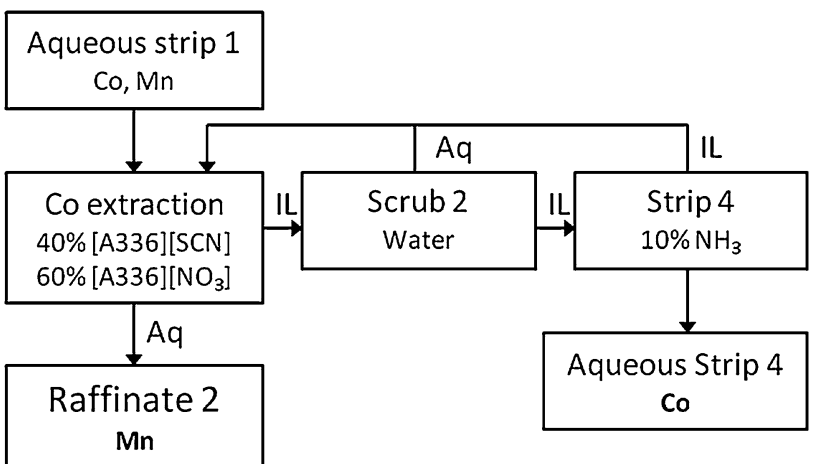

Fig. 5 Flow sheet describing the separation of cobalt from manganese

ionic liquid supplied the nitrate ions necessary for the extraction of rare earths. The viscosity of the different steps is highly dependent on the temperature and metal loading. An elevated temperature is necessary for process conditions. A flow sheet describing the process has been proposed for the use of $15 \%(\mathrm{v} / \mathrm{v})$ Cyanex 923 in [A336] $\left[\mathrm{NO}_{3}\right.$ ] in order to separate the metals used in NiMH batteries into four groups by selective stripping. The cobalt and manganese in the aqueous solution in the nitrate-based strip step were successfully separated using [A336][SCN].

Acknowledgments The authors thank the KU Leuven for financial support (GOA project 13/008 and IOF-KP RARE ${ }^{3}$ ).

\section{References}

1. Binnemans K, Jones PT, Blanpain B, Van Gerven T, Yang Y, Walton A, Buchert M (2013) Recycling of rare earths: a critical review. J Clean Prod 51:1-22

2. Larsson K, Ekberg C, Ødegaard-Jensen A (2013) Dissolution and characterization of HEV NiMH batteries. Waste Manage 33:689698

3. Zhang P, Yokoyama T, Itabashi O, Wakui Y, Suzuki TM, Inoue K (1998) Hydrometallurgical process for recovery of metal values from spent nickel-metal hydride secondary batteries. Hydrometallurgy 50(1):61-75

4. Tzanetakis N, Scott K (2004) Recycling of nickel-metal hydride batteries. I: dissolution and solvent extraction of metals. J Chem Technol Biotechnol 79:919-926

5. Tzanetakis N, Scott K (2004) Recycling of nickel-metal hydride batteries. II: electrochemical deposition of cobalt and nickel. J Chem Technol Biotechnol 79:927-934

6. Fernandes A, Afonso JC, Dutra AJ (2013) Separation of nickel(II), cobalt(II) and lanthanides from spent Ni-MH batteries by hydrochloric acid leaching, solvent extraction and precipitation. Hydrometallurgy 133:37-43

7. Larsson K, Ekberg C, Ødegaard-Jensen A (2012) Using Cyanex 923 for selective extraction in a high concentration chloride medium on nickel metal hydride battery waste. Hydrometallurgy 129-130:35-42

8. Larsson K, Ekberg C, Ødegaard-Jensen A (2013) Using Cyanex 923 for selective extraction in a high concentration chloride medium on nickel metal hydride battery waste. part II: Mixersettler experiments. Hydrometallurgy 133:168-175 
9. Visser AE, Swatloski RP, Griffin ST, Hartman DH, Rogers RD (2001) Liquid/liquid extraction of metal ions in room temperature ionic liquids. Sep Sci Technol 36(5-6):785-804

10. Billard I, Ouadi A, Gaillard C (2011) Liquid-liquid extraction of actinides, lanthanides, and fission products by use of ionic liquids: from discovery to understanding. Anal Bioanal Chem 400:1555-1566

11. Wellens S, Goovaerts R, Möller C, Luyten J, Thijs B, Binnemans $\mathrm{K}$ (2013) A continuous ionic liquid extraction process for the separation of cobalt from nickel. Green Chem 15:3160-3164

12. Plechkova NV, Seddon KR (2008) Applications of ionic liquids in the chemical industry. Chem Soc Rev 37:123-150

13. Kubota F, Goto M (2006) Application of ionic liquids to solvent extraction. Solvent Extr Res Dev Jpn 13:23-36

14. Dai S, Ju YH, Barnes CE (1999) Solvent extraction of strontium nitrate by a crown ether using room-temperature ionic liquids. J Chem Soc Dalton Trans 8:1201-1202

15. Nakashima K, Kubota F, Maruyama T, Goto M, Maruyama T (2005) Feasibility of ionic liquids as alternative separation media for industrial solvent extraction processes. Ind Eng Chem Res 44:4368-4372

16. Liu Y, Chen J, Li D (2012) Application and perspective of ionic liquids on rare earths green separation. Sep Sci Technol 47(2):223-232

17. Han X, Armstrong DW (2007) Ionic liquids in separations. Acc Chem Res 40(11):1079-1086

18. Earle MJ, Seddon KR (2000) Ionic liquids. Green solvents for the future. Pure Appl Chem 72(7):1391-1398

19. Larsson K, Binnemans K (2014) Selective extraction of metals using ionic liquids for nickel metal hydride battery recycling. Green Chem 16:4595-4603

20. Larsson K, Binnemans K (2015) Separation of rare earths by split-anion extraction. Hydrometallurgy (in revision)

21. Mikkola JP, Virtanen P, Sjöholm R (2006) Aliquat 336 a versatile and affordable cation source for an entirely new family of hydrophobic ionic liquids. Green Chem 8:250-255 